\title{
Cutting Geometry and Base-Cone Parameters of Manufacturing Hypoid Gears by Generating-Line Method
}

\author{
Linan $\mathrm{Li}^{*}$, Zhaojun Yang, Yankun Wang and Xuecheng Zhang
}

School of Mechanical Science and Engineering, Jilin University, Changchun 130025, China

\begin{abstract}
Generating-line method, which is based on the generating process of spherical involute curve, is a new processing theory of cutting ideal spherical involute gears. Based on the principle of the new method, this paper expands the traditional geometrical relationship into the cutting geometry of generating-line method, and proposes the base-cone parameters with their formulas to provide necessary parameters for further study. The application examples, such as establishing the coordinate systems and the equation of gear generating line, show the importance of these researches, and the example of calculating geometric parameters illustrate the way to adjust the base-cone parameters. It can be seen from the researches, the cutting geometry contains the tangent relationships between two base cones and a base plane respectively, and the planar conjugated relationship between two generating lines of pinion and gear. The base-cone parameters determine the relationships among base cones, base plane and generating lines. If some of the base-cone parameters need to be adjusted, it can be realized by modify the value of the parameter $r_{2}, \varepsilon$ or $Z_{0}$.
\end{abstract}

Keywords: Hypoid gear, generating-line method, cutting geometry, base-cone parameters.

\section{INTRODUCTION}

Hypoid gears are widely used to transmit crossed-axis power and motion in vehicles, ships and aircrafts, and could offer higher load capability and axis position flexibility than spiral bevel gears. The basic geometry of hypoid gears were established by Wildhaber [1] and Baxter [2], after decades of development, there are two major processes called face milling and face hobbing for cutting hypoid and spiral bevel gears in the current gear manufacturing industry [3].

In recent years, a large number of developments in the field of manufacturing spiral bevel and hypoid gears have been obtained. Qi Fan developed mathematical models of hypoid gear drives processed by face milling and face hobbing, and researched the tooth contact analysis and the tooth surface error correction [4-6]; in order to improve the load distribution and reduce the transmission error, Vilmos Simon proposed the optimal machine tool setting and tooth modifications of spiral bevel and hypoid gears [7-9]. All of these developments above were built on the traditional methods of face milling and face hobbing. As a result of applying engineering approximation, the tooth profile curves cut by these methods are not ideal spherical involutes, therefore the advantages of using spherical involute profiles, such as transmission ratio constancy and angular displacement insensitivity, are partly lost. Also the calculation and adjustment of machine tool settings are complex, and the interchangeability of the gears cut by these traditional methods is relatively poor [10]. Y.C. Tsai et al. [11] and M.J. Al-Daccak et al. [12] respectively proposed the modeling of bevel gears by using exact spherical involute profiles, but they did not discuss the feasibility of cutting ideal spherical involute gears.

*Address correspondence to this author at the School of Mechanical Science and Engineering, Jilin University, Changchun 130025, China; Tel: +86-43185095839(office); +86-13844010585 (Mobile); Fax: +86-431-85095839;

E-mails: lilinan@foxmail.com,weblln2008@gmail.com
Based on the generating principle of spherical involute and the theory of conjugated tooth surfaces, we have proposed the generating-line method of cutting spherical involute gears [13, 14]. This new theory can be used to process ideal spherical involute bevel gears; however the principle of cutting hypoid gears by this method still needs to be researched systematically. Therefore, in order to facilitate the further studies of the shape of generating lines and the cutting motion parameters, this paper develops the cutting geometry and base-cone parameters of manufacturing hypoid gears by this new method, and indicates the important effects of the researches through the application examples.

\section{BASIC GEOMETRY}

The axodes of hypoid gears are two tangent revolving hyperboloids. In order to simplify the designing and manufacturing, axodes are usually replaced by a pair of pitch cones [15]. As shown in Fig. (1a), the angle between pinion axis $\mathrm{X}_{1}$ and gear axis $\mathrm{X}_{2}$ is shaft angle $\Sigma$, and the length of common perpendicular $\mathrm{O}_{1} \mathrm{O}_{2}$ is the pinion offset $E$; two pitch cones are in tangency at point $\mathrm{M}$ which is usually the center point of the tooth surfaces, and the common tangent plane, which is also called pitch plane, is $\mathrm{T}$; at point $\mathrm{M}$, pitch cone distances of pinion and gear are $A_{1}$ and $A_{2}$, and pitch radius are $r_{1}$ and $r_{2}$; pitch angles are $\delta_{1}$ and $\delta_{2}$, and the distance from point $\mathrm{O}_{2}$ to the center of gear pitch circle is $Z_{0}$; the pitch cone vertexes of pinion and gear are $\mathrm{H}_{1}$ and $\mathrm{H}_{2}$, and the angle between $\mathrm{H}_{1} \mathrm{M}$ and $\mathrm{H}_{2} \mathrm{M}$ is $\varepsilon^{\prime}$; the line $\mathrm{K}_{1} \mathrm{~K}_{2}$, which crosses the point $M$ and is vertical to the $T$ plane, intersects $X_{1}$ and $X_{2}$ at points $K_{1}$ and $K_{2}$; in the vertical plane of axis $X_{1}$, the angle between projections of $\mathrm{X}_{2}$ and $\mathrm{K}_{1} \mathrm{~K}_{2}$ is $\eta$; in the vertical plane of axis $\mathrm{X}_{2}$, the angle between projections of $\mathrm{X}_{1}$ and $\mathrm{K}_{1} \mathrm{~K}_{2}$ is $\varepsilon$. As shown in Fig. (1b), in the pitch plane $\mathrm{T}$, the helix angles at the point $\mathrm{M}$ of pinion and gear are $\beta_{1}$ and $\beta_{2}$, and this paper calls $\beta_{1}$ and $\beta_{2}$ pitch helix angles. In addition, the number of teeth of pinion and gear are $N_{1}$ and $N_{2}$. 


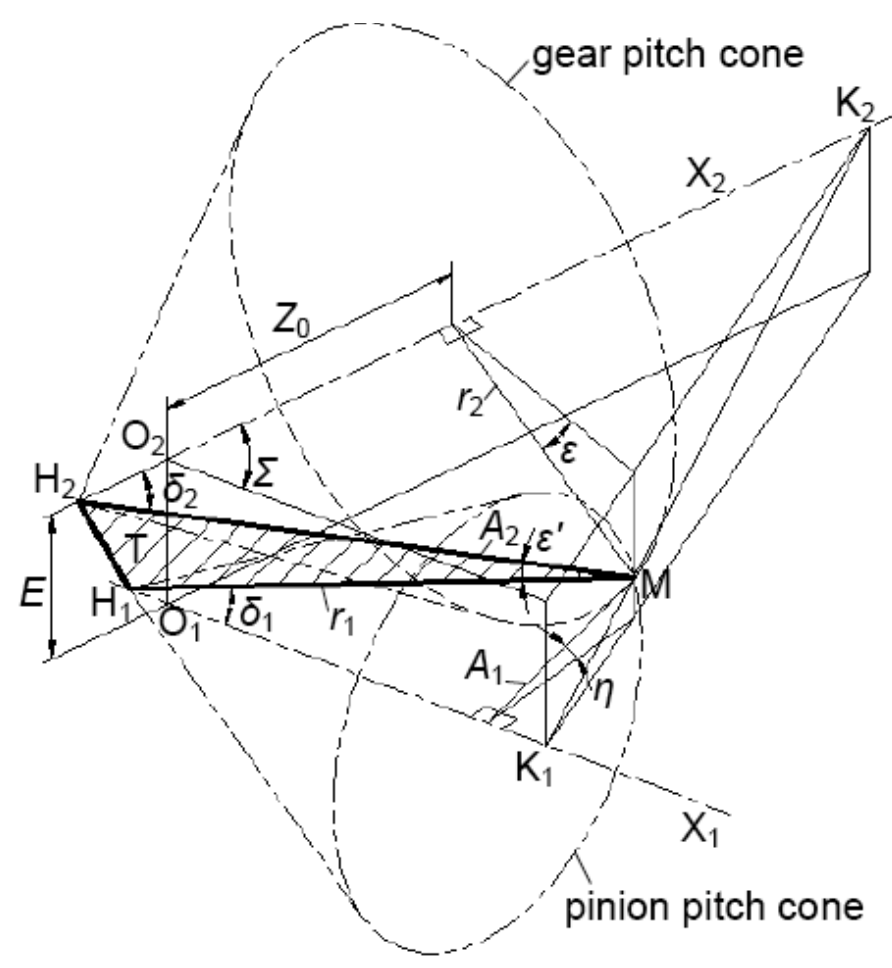

a

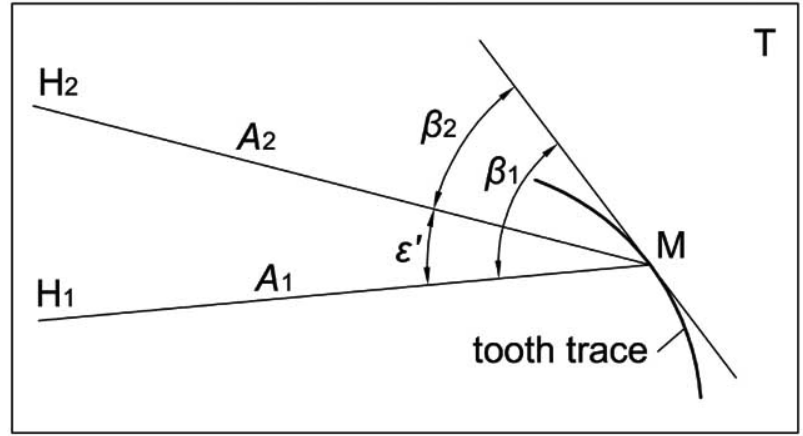

b

Fig. (1). Basic geometry of hypoid gears.

The position of point $\mathrm{M}$ can be determined by given the parameters $r_{2}, \varepsilon$ and $Z_{0}$, if we know the parameters $N_{1}, N_{2}, \Sigma$, $E$ and the position of point $\mathrm{M}$, all of other parameters mentioned above can also be determined uniquely [2]. Hypoid gears can be designed and manufactured by traditional methods according to this basic geometry. But for the new generating-line method in this paper, this geometry needs to be expanded according to the new cutting principle.

\section{CUTTING GEOMETRY OF GENERATING-LINE METHOD}

For a bevel gear drive, as shown in Fig. (2), pitch plane T and two pitch cones are in tangency alone line OM, while base plane $\mathrm{Q}$ and two base cones are in tangency alone line $\mathrm{OU}_{1}$ and $\mathrm{OU}_{2}$, and the angle $\alpha$ between plane $\mathrm{T}$ and plane $\mathrm{Q}$ is the pressure angle on the back cone. When the motion of

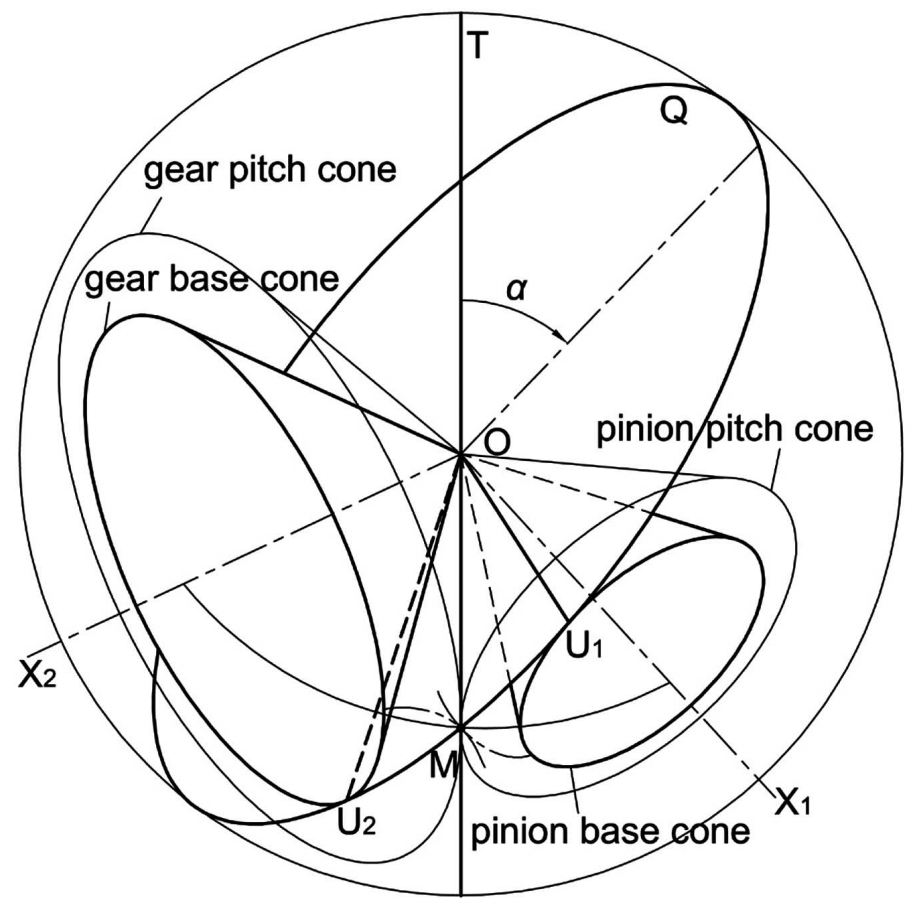

Fig. (2). Schematic of a bevel gear drive. 
this pair of pitch cones is pure-rolling in tangency with the pitch plane $\mathrm{T}$, the motions of two base cones are also purerolling in tangency with the base plane $\mathrm{Q}$ along their own tangent lines respectively, and a pair of ideal spherical involutes with respect to the base cones could be formed by the traces of point $\mathrm{M}$ which is fixed on and rolling with the plane Q.

As shown in Fig. (3), $\mathrm{M}^{\prime} \mathrm{C}^{\prime}$ and $\mathrm{M}^{\prime \prime} \mathrm{C}^{\prime \prime}$ are two spherical involutes on the toe and on the heel of gear respectively; if there is a curve between $\mathrm{M}^{\prime}$ and $\mathrm{M}^{\prime \prime}$ in plane $\mathrm{Q}$, a spherical involute profile tooth surface will be formed between toe and heel of the gear. According to this theory, generating-line method takes generating line $\mathrm{M}^{\prime} \mathrm{M}^{\prime \prime}$ as the cutting edge, which removes excess material with the appropriate relative motion between tool and gear blanks. In theory, using the same generating line as the cutting edge could process a pair of bevel gears which are conjugated in line contact.

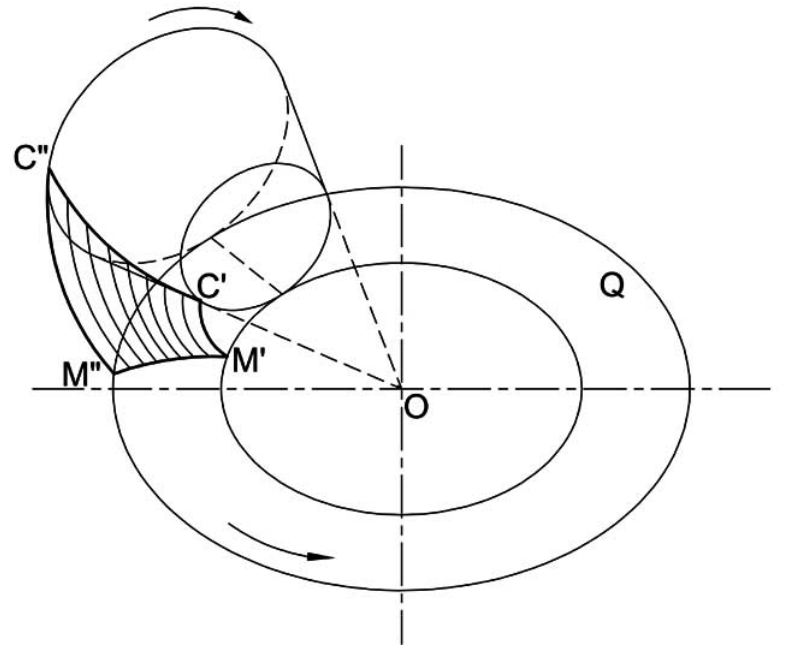

Fig. (3). Principle of generating-line method.

As can be seen from the description above, determining the position of base plane $\mathrm{Q}$ and the equation of generating line is the key point of the generating-line method. Therefore, this new method could also be used to cut hypoid gears if these two elements can be determined properly. However, traditional methods of designing and manufacturing hypoid gears do not have the concepts of base cone and base plane, so this paper proposes the following method to establish the base cones and base plane of hypoid gears.

As shown in Fig. (4), the final position of rotating pitch plane $\mathrm{T}$ about $\mathrm{H}_{2} \mathrm{M}$ at an angle $\alpha$ could be defined as plane $\mathrm{Q}$ which is the base plane of a hypoid gear drive; the axis $\mathrm{X}_{1}$ and plane $\mathrm{Q}$ intersect at point $\mathrm{V}$, and the tangent relationship between plane $\mathrm{Q}$ and two base cones can be used to determine base cones of the pinion and the gear; the tangent lines are $\mathrm{VU}_{1}$ and $\mathrm{H}_{2} \mathrm{U}_{2}$, and the base angles of pinion and gear are $\delta_{b 1}$ and $\delta_{b 2}$.

As the base cone vertexes of pinion and gear are not coincident, the generating lines of pinion and gear can not be the same one. Therefore as shown in Fig. (5), the generating planes $\mathrm{Q}_{1}$ and $\mathrm{Q}_{2}$ are set up in the base plane $\mathrm{Q}$. When the gears are being processed or driving, the motion of pinion base cone and the generating plane $\mathrm{Q}_{1}$ are pure-rolling in tangency along $\mathrm{VU}_{1}$, while the motion of gear base cone and the generating plane $\mathrm{Q}_{2}$ are pure-rolling in tangency along
$\mathrm{H}_{2} \mathrm{U}_{2}$. Based on the principles of gear connection, it can be proved that if the following two conditions are met, a pair of hypoid gears cut by generating-line method will be conjugated in point contact.

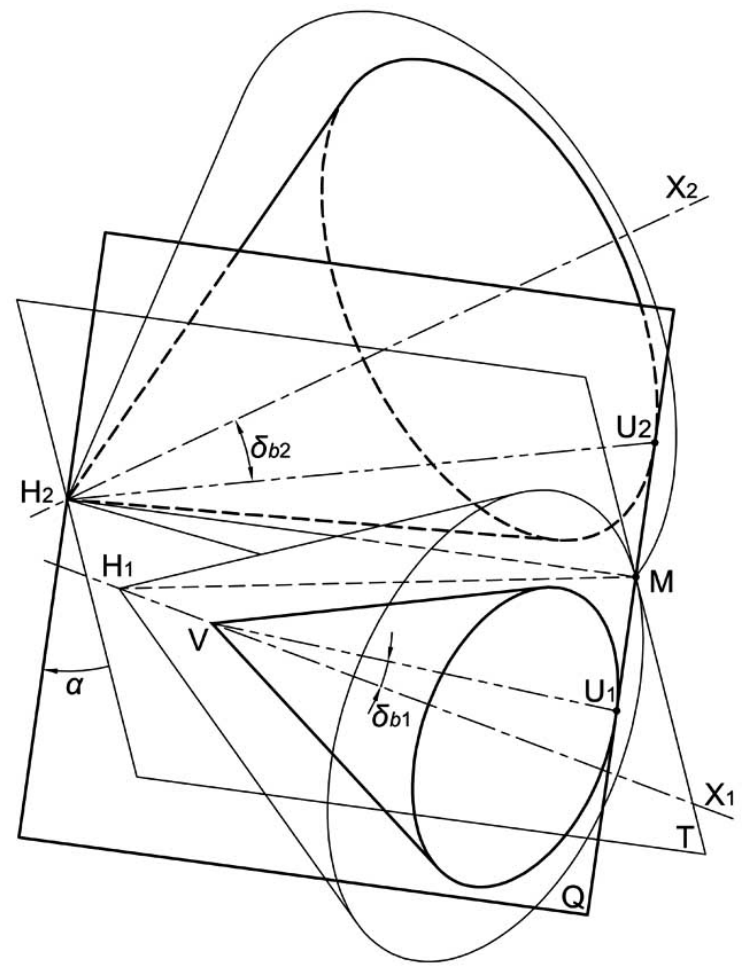

Fig. (4). Geometry of cutting hypoid gears.

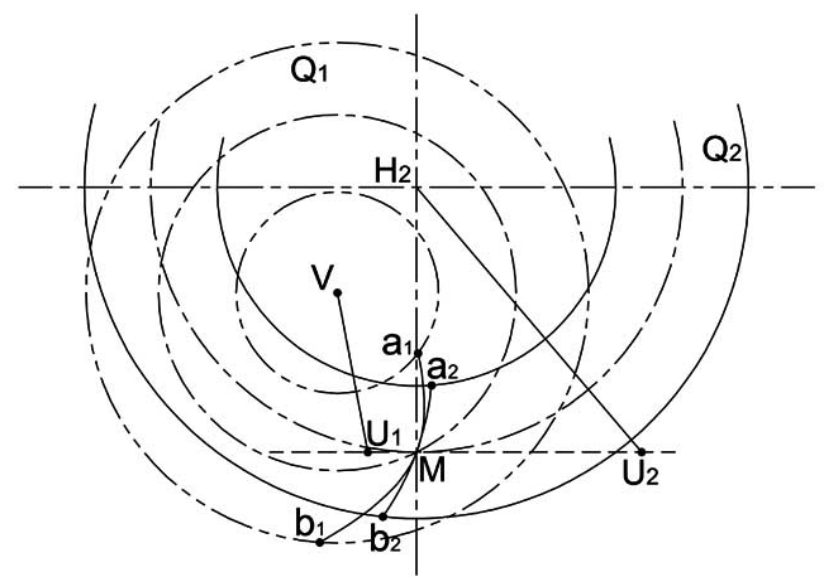

Fig. (5). Relationship of generating lines.

Condition 1: The rotation speeds of generating plane $\mathrm{Q}_{1}$ and $\mathrm{Q}_{2}$ meet the transmission ratio of the gears.

Condition 2: As the pinion generating line $a_{1} b_{1}$ rotates with $\mathrm{Q}_{1}$ and the gear generating line $\mathrm{a}_{2} \mathrm{~b}_{2}$ rotates with $\mathrm{Q}_{2}, \mathrm{a}_{1} \mathrm{~b}_{1}$ and $a_{2} b_{2}$ is a pair of planar conjugated curves, while point $M$ was one of their contact points, and there is no curvature interference between the two generating lines.

Because the shape of generating lines have not been determined, similar to the concepts of the convex and concave of spiral bevel gears, this paper defines the left and 


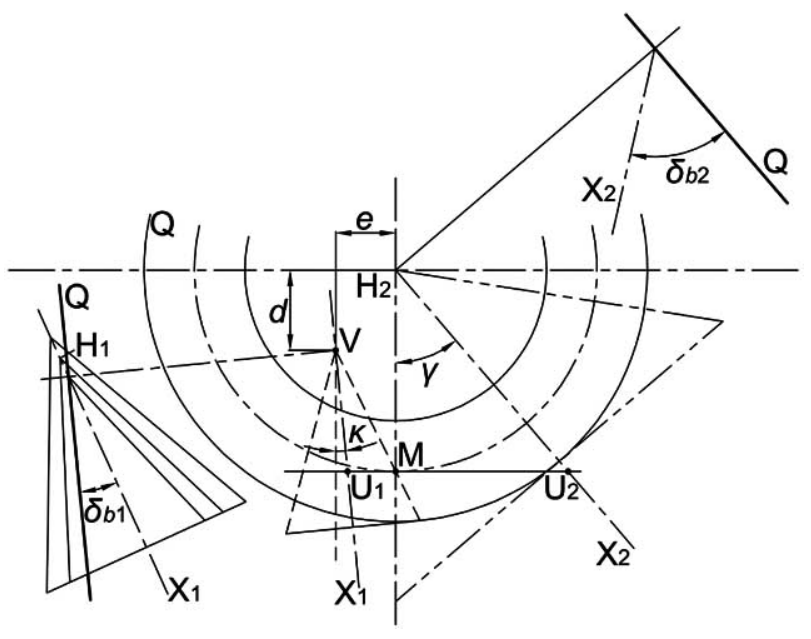

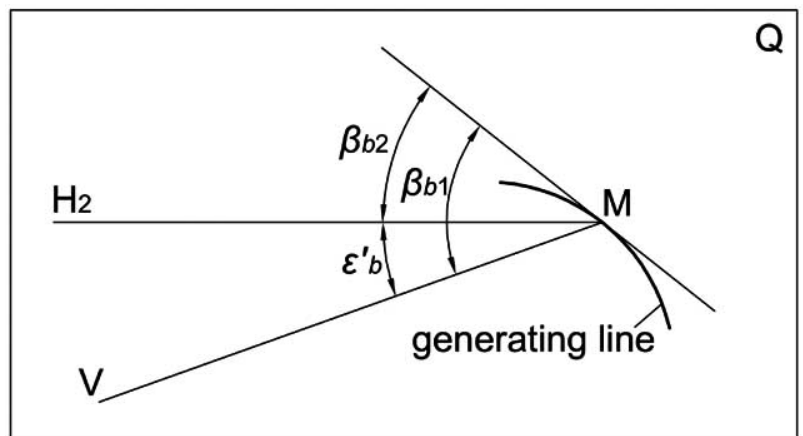

b

Fig. (6). Schematic of base-cone parameters.

right sides of tooth surfaces of hypoid gears as follows: observing a gear tooth alone the tooth trace from the heel to the toe, putting the topland above and the root below, and then two sides of the tooth in sight are called the left side and right side respectively. Therefore, the situation shown in Fig. (4) is the geometry of cutting left sides of tooth surfaces of hypoid gears which the pinion is offset below from the center of the gear, and this paper mainly researches the situation of cutting left sides of tooth surfaces, if the angle $\alpha$ is rotating to the opposite direction, the cutting geometry of right sides of tooth surfaces can be easily obtained.

\section{BASE-CONE PARAMETERS}

In order to facilitate the further studies of the parameters of the machine tool and the blade, it is necessary to determine the geometrical relationships among base cones, base plane and generating lines. On base of the cutting geometry as shown in Fig. (6), this paper defines the basecone parameters as below to determine those geometrical relationships.

On the basis of designing, assume the pitch-cone pressure angle $\alpha_{n}$, which indicates the angle between normal direction of the tooth surface and the pitch plane $\mathrm{T}$ at point $\mathrm{M}$, is known. Then the angle $\alpha$ between pitch plane $\mathrm{T}$ and base plan Q can be determined by

$\alpha=\sin ^{-1} \frac{\sin \alpha_{n}}{\sqrt{1-\cos ^{2} \alpha_{n} \sin ^{2} \beta_{2}}}$

The base cone angles of pinion and gear are determined, respectively, by

$\delta_{b 1}=\sin ^{-1}\left(\cos \alpha \sin \delta_{1}+\sin \alpha \cos \delta_{1} \sin \varepsilon^{\prime}\right)$

$\delta_{b 2}=\tan ^{-1} \sqrt{\frac{\sin ^{2} \delta_{2}}{\tan ^{2} \alpha+\cos ^{2} \delta_{2}}}$

As shown in Fig. (6a), in the base plane Q, $d$ denotes the distance from the projection of point $\mathrm{V}$ on the line $\mathrm{H}_{2} \mathrm{M}$ to point $\mathrm{H}_{2}$, provided $d$ is positive if the projective point lies between $\mathrm{M}$ and $\mathrm{H}_{2}$; otherwise, $d$ is negative. Furthermore, $e$ denotes the distance from point $\mathrm{V}$ to line $\mathrm{H}_{2} \mathrm{M} ; \kappa$ denotes the angle between $\mathrm{VU}_{1}$ and $\mathrm{H}_{2} \mathrm{M}$; and $\gamma$ denotes the angle between $\mathrm{H}_{2} \mathrm{U}_{2}$ and $\mathrm{H}_{2} \mathrm{M}$. These parameters are determined, respectively, by

$$
\begin{aligned}
& d=A_{2}-\frac{A_{1} \tan \delta_{1} \cos \varepsilon^{\prime}}{\tan \alpha \sin \varepsilon^{\prime}+\tan \delta_{1}} \\
& e=\frac{A_{1} \sin \delta_{1} \sin \varepsilon^{\prime}}{\cos \alpha \sin \delta_{1}+\sin \alpha \cos \delta_{1} \sin \varepsilon^{\prime}} \\
& \kappa=\tan ^{-1}\left(\frac{\sin \varepsilon^{\prime} \cos \alpha-\sin \alpha \tan \delta_{1}}{\cos \varepsilon^{\prime}}\right) \\
& \gamma=\cos ^{-1} \frac{\cos \delta_{2}}{\cos \delta_{b 2}}
\end{aligned}
$$

As shown in Fig. (6b), in the base plane Q, $\varepsilon_{b}^{\prime}$ denotes the angle between $\mathrm{VM}$ and $\mathrm{H}_{2} \mathrm{M} ; \beta_{b 1}$ denotes the angle between the tangential direction of generating lines at point $\mathrm{M}$ and $\mathrm{VM}$, and $\beta_{b 2}$ denotes the angle between the tangential direction of generating lines at point $\mathrm{M}$ and $\mathrm{H}_{2} \mathrm{M}$, so this paper calls $\beta_{b 1}$ and $\beta_{b 2}$ base helix angles. These parameters are determined, respectively, by

$$
\begin{aligned}
& \varepsilon_{b}^{\prime}=\tan ^{-1} \frac{e}{A_{2}-d} \\
& \beta_{b 2}=\tan ^{-1}\left(\cos \alpha \tan \beta_{2}\right) \\
& \beta_{b 1}=\beta_{b 2}+\varepsilon_{b}
\end{aligned}
$$

\section{APPLICATION EXAMPLES}

Based on the researches of the cutting geometry and the base-cone parameters, many further researches can be done, such as establishing the coordinate systems to build the tooth 


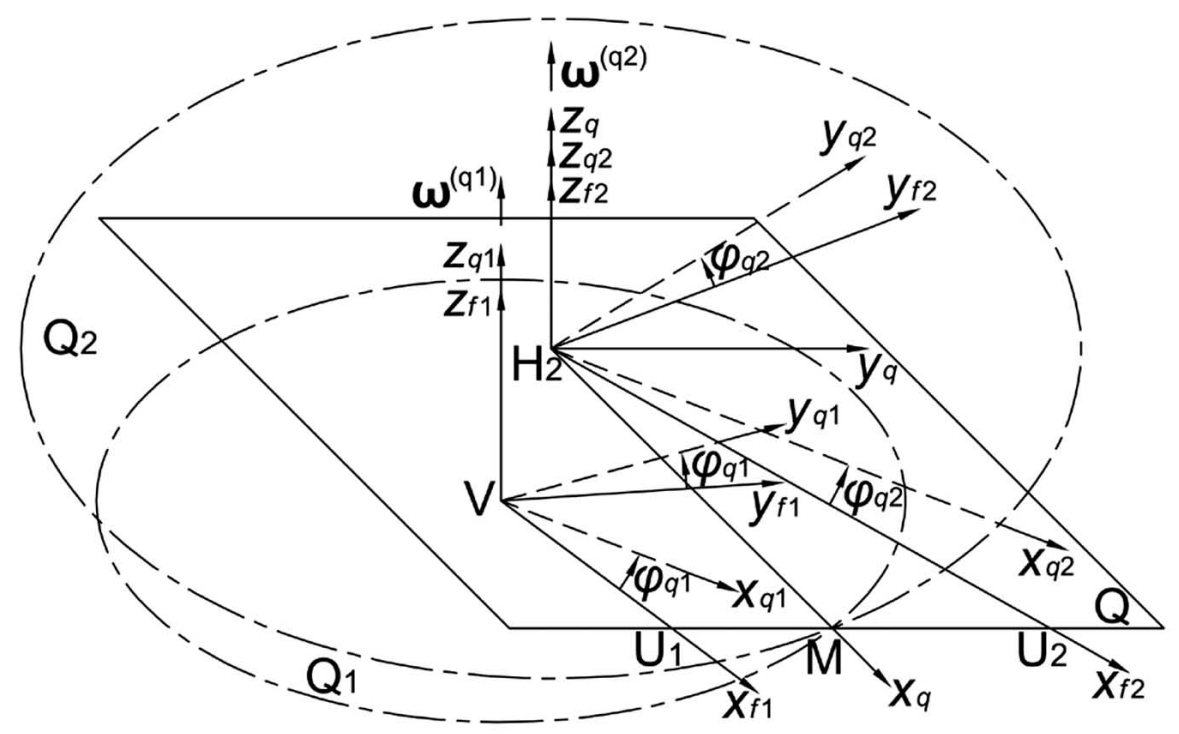

Fig. (7). Coordinate systems $S_{q}, S_{f 1}, S_{f 2}, S_{q 1}, S_{q 2}$.

surfaces model and analyze the situation of meshing, establishing the equation of gear generating line to study the shape of generating lines and the influence of shape errors, and so on.

\subsection{Coordinate Systems}

As shown in Fig. (7) and Fig. (8), the coordinate systems $S_{q}, S_{f 1}, S_{f 2}, S_{q 1}, S_{q 2}, S_{1}$ and $S_{2}$ are established as given below.

Fixed system $S_{q}\left(x_{q}, y_{q}, z_{q}\right)$ is fixed with the initial position of plane $\mathrm{Q}$ and attached to the machine house.

Auxiliary fixed systems $S_{f 1}\left(x_{f 1}, y_{f 1}, z_{f 1}\right)$ and $S_{f 2}\left(x_{f 2}, y_{f 2}, z_{f 2}\right)$ are fixed with the initial positions of generating planes $\mathrm{Q}_{1}$ and $\mathrm{Q}_{2}$ respectively.

Moving systems $S_{q 1}\left(x_{q 1}, y_{q 1}, z_{q 1}\right)$ and $S_{q 2}\left(x_{q 2}, y_{q 2}, z_{q 2}\right)$ are fixed with generating planes $\mathrm{Q}_{1}$ and $\mathrm{Q}_{2}$ respectively, and simulated motions of cutting edges. $S_{q 1}$ and $S_{q 2}$ are supposed to rotate about $z_{q 1}$ and $z_{q 2}$ respectively with the angular velocity $\boldsymbol{\omega}^{(\mathrm{q} 1)}$ and $\boldsymbol{\omega}^{(\mathrm{q} 2)}$, and the rotation angles starting from the initial positions are $\varphi_{q 1}$ and $\varphi_{q 2}$.

Moving systems $S_{1}\left(x_{1}, y_{1}, z_{1}\right)$ and $S_{2}\left(x_{2}, y_{2}, z_{2}\right)$ are fixed with base cones and simulated motions of gear blanks. The initial position of $S_{1}$ is the position of rotating $S_{f 1}$ about $y_{f 1}$ at an angle $\delta_{b 1}$, and the initial position of $S_{2}$ is the position of rotating $S_{f 2}$ about $y_{f 2}$ at an angle $\delta_{b 2}$. $S_{1}$ and $S_{2}$ are supposed to rotate about $x_{1}$ and $x_{2}$ respectively with the angular velocity $\boldsymbol{\omega}^{(1)}$ and $\boldsymbol{\omega}^{(2)}$, and the rotation angles starting from the initial positions are $\varphi_{1}$ and $\varphi_{2}$.

Then, on the basis of the cutting geometry and base-cone parameters proposed above, the transformation matrixes can be determined as below.

$\mathbf{M}_{q_{-} f 1}=\left[\begin{array}{cccc}\cos \kappa & -\sin \kappa & 0 & d \\ \sin \kappa & \cos \kappa & 0 & -e \\ 0 & 0 & 1 & 0 \\ 0 & 0 & 0 & 1\end{array}\right]$

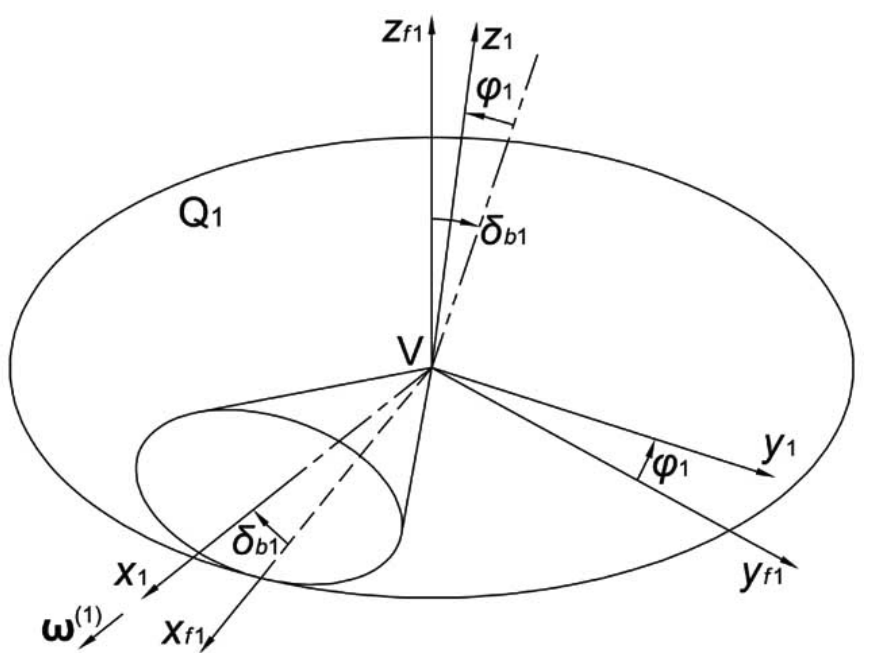

a

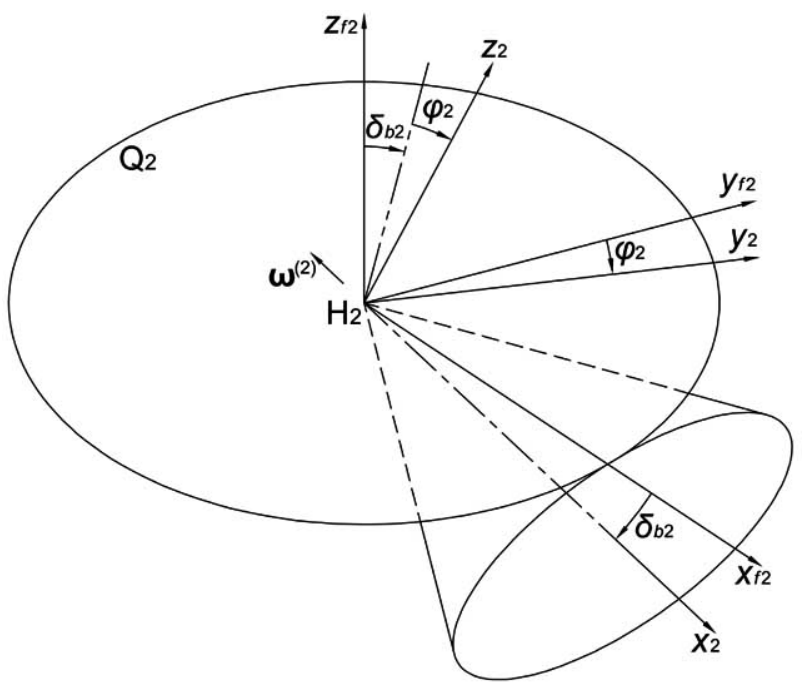

b

Fig. (8). Coordinate systems $S_{1}, S_{2}$. 


$$
\begin{aligned}
\mathbf{M}_{q_{-} f 2}=\left[\begin{array}{cccc}
\cos \gamma & -\sin \gamma & 0 & 0 \\
\sin \gamma & \cos \gamma & 0 & 0 \\
0 & 0 & 1 & 0 \\
0 & 0 & 0 & 1
\end{array}\right] & \begin{array}{c}
\theta=-\beta_{b 2}-\gamma \\
\text { If the gear generating line }
\end{array} \\
\mathbf{M}_{f 1 q 1}=\left[\begin{array}{cccc}
\cos \phi_{q 1} & -\sin \phi_{q 1} & 0 & 0 \\
\sin \phi_{q 1} & \cos \phi_{q 1} & 0 & 0
\end{array}\right] & \left\{\begin{array}{l}
x_{q 2 c}(\theta)=x_{0}+r \cos (\theta+\mu) \\
y_{q 2 c}(\theta)=y_{0}+r \sin (\theta+\mu) \\
z_{q 2 c}(\theta)=0
\end{array}\right.
\end{aligned}
$$$$
\mathbf{M}_{f 1 \_q 1}=\left[\begin{array}{cccc}
\cos \phi_{q 1} & -\sin \phi_{q 1} & 0 & 0 \\
\sin \phi_{q 1} & \cos \phi_{q 1} & 0 & 0 \\
0 & 0 & 1 & 0 \\
0 & 0 & 0 & 1
\end{array}\right]
$$$$
\mathbf{M}_{f 2 \_q 2}=\left[\begin{array}{cccc}
\cos \phi_{q 2} & -\sin \phi_{q 2} & 0 & 0 \\
\sin \phi_{q 2} & \cos \phi_{q 2} & 0 & 0 \\
0 & 0 & 1 & 0 \\
0 & 0 & 0 & 1
\end{array}\right]
$$$$
\mathbf{M}_{f 1 \_1}=\left[\begin{array}{cccc}
\cos \delta_{b 1} & -\sin \delta_{b 1} \sin \phi_{1} & -\sin \delta_{b 1} \cos \phi_{1} & 0 \\
0 & \cos \phi_{1} & -\sin \phi_{1} & 0 \\
\sin \delta_{b 1} & \cos \delta_{b 1} \sin \phi_{1} & \cos \delta_{b 1} \cos \phi_{1} & 0 \\
0 & 0 & 0 & 1
\end{array}\right]
$$$$
\mathbf{M}_{f 2 \_2}=\left[\begin{array}{cccc}
\cos \delta_{b 2} & -\sin \delta_{b 2} \sin \phi_{2} & \sin \delta_{b 2} \cos \phi_{2} & 0 \\
0 & \cos \phi_{2} & \sin \phi_{2} & 0 \\
-\sin \delta_{b 2} & -\cos \delta_{b 2} \sin \phi_{2} & \cos \delta_{b 2} \cos \phi_{2} & 0 \\
0 & 0 & 0 & 1
\end{array}\right]
$$

where matrix $\mathbf{M}_{q_{-} f 1}$ denotes the coordinate transformation from system $S_{f 1}$ to $S_{q}$, and other matrix have the same subscript meaning.

\subsection{Equation of Gear Generating-Line}

To make the structure and movement of machine tool simple, the shape of generating lines should be simple and easy to form a continuous movement. Therefore the most appropriate shapes are straight line and circular arc. In order to improve processing efficiency, the shape of the gear generating line should be determined preferentially.

If the gear generating line $a_{2} b_{2}$ is a straight line, then its equation in coordinate system $\mathrm{S}_{\mathrm{q} 2}$ should be represented as,

$$
\left\{\begin{array}{l}
x_{q 2 c}(u)=x_{1}+u \cos \theta \\
y_{q 2 c}(u)=y_{1}+u \sin \theta \\
z_{q 2 c}(u)=0
\end{array}\right.
$$

where $u$ is a parameter, $x_{1}, y_{1}$ and $\theta$ can be determined by the cutting geometry and the base-cone parameters, namely,

$\left\{\begin{array}{l}x_{1}=A_{2} \cos \gamma \\ y_{1}=-A_{2} \sin \gamma\end{array}\right.$
If the gear generating line $a_{2} b_{2}$ is a circular arc, then its equation in coordinate system $\mathrm{S}_{\mathrm{q} 2}$ should be represented as

where $\theta$ is a parameter, $r$ is the arc radius of gear generating line, $x_{0}, y_{0}$ and $\mu$ can be determined by the cutting geometry and the base-cone parameters, namely

$$
\begin{aligned}
& \left\{\begin{array}{c}
x_{0}=A_{2} \cos \gamma-r \sin \left(\beta_{b 2}+\gamma\right) \\
y_{0}=-A_{2} \sin \gamma-r \cos \left(\beta_{b 2}+\gamma\right)
\end{array}\right. \\
& \mu=90^{\circ}-\beta_{b 2}-\gamma
\end{aligned}
$$

\subsection{Example of Calculating Geometric Parameters}

Consulting the data of designing a pair of Gleason hypoid gears, mainly geometrical parameters of cutting hypoid gears by generating-line method can be calculated as follows.

The basic parameters are shown in Table $\mathbf{1}$, and these parameters are given by the basic conditions of designing. As shown in Table 2, the key geometrical parameters $r_{2}, \varepsilon$ and $Z_{0}$, which determining the position of point $\mathrm{M}$, are assumed known based on the data of Gleason gears, and so is the average pressure angle $\alpha^{*}$. Then, on the basis of traditional formulas, the basic geometrical parameters can be calculated easily, the results are shown in Table 3. Finally, based on the equations (1) to (10), the results of the basecone parameters are calculated and shown in Table 4.

Table 1. The Basic Parameters of Designing

\begin{tabular}{|c|c|c|c|}
\hline Symbols & Data & Symbols & Data \\
\hline \hline$N_{1}$ & 11 & $\Sigma(\mathrm{deg})$ & 90 \\
\hline$N_{2}$ & 43 & $E(\mathrm{~mm})$ & 34 \\
\hline
\end{tabular}

Table 2. The Key Geometrical Parameters Assumed in Advance

\begin{tabular}{|c|c|c|c|}
\hline Symbols & Data & Symbols & Data \\
\hline \hline$r_{2}(\mathrm{~mm})$ & 88.16 & $Z_{0}(\mathrm{~mm})$ & 30.56 \\
\hline$\varepsilon(\mathrm{deg})$ & 20.3 & $\alpha^{*}(\mathrm{deg})$ & 19 \\
\hline
\end{tabular}

Table 3. The Results of the Basic Geometrical Parameters

\begin{tabular}{|c|c|c|c|}
\hline Symbols & Data & Symbols & Data \\
\hline \hline$r_{1}(\mathrm{~mm})$ & 30.688 & $A_{2}(\mathrm{~mm})$ & 92.618 \\
\hline$\eta(\mathrm{deg})$ & 6.375 & $\varepsilon^{\prime}(\mathrm{deg})$ & 21.237 \\
\hline$\delta_{1}(\mathrm{deg})$ & 16.707 & $\beta_{1}(\mathrm{deg})$ & 49.981 \\
\hline$\delta_{2}(\mathrm{deg})$ & 72.151 & $\beta_{2}(\mathrm{deg})$ & 28.744 \\
\hline$A_{1}(\mathrm{~mm})$ & 106.964 & $\alpha_{n}(\mathrm{deg})$ & 25.668 \\
\hline
\end{tabular}


Table 4. The Results of the Base-Cone Parameters

\begin{tabular}{|c|c|c|c|}
\hline Symbols & Data & Symbols & Data \\
\hline \hline$\alpha(\mathrm{deg})$ & 28.728 & $\kappa(\mathrm{deg})$ & 10.537 \\
\hline$\delta_{b 1}(\mathrm{deg})$ & 24.762 & $\gamma(\mathrm{deg})$ & 56.180 \\
\hline$\delta_{b 2}(\mathrm{deg})$ & 56.585 & $\varepsilon_{b}^{\prime}(\mathrm{deg})$ & 23.901 \\
\hline$d(\mathrm{~mm})$ & 32.611 & $\beta_{b 1}(\mathrm{deg})$ & 49.588 \\
\hline$e(\mathrm{~mm})$ & 26.593 & $\beta_{b 2}(\mathrm{deg})$ & 25.686 \\
\hline
\end{tabular}

During the process of researching the shape of generating lines, the parameters of the gear generating line could influence the shape of the pinion generating line, and we can see from the conditions above, the parameters of the gear generating line are determined by the base-cone parameters. Therefore, when some of the base-cone parameters need to be adjusted to optimize the shape of the pinion generating line, it can be realized by modify the value of the parameter $r_{2}, \varepsilon$ or $Z_{0}$. For example, if the value of $Z_{0}$ is changed from 30.56 to 30.00 , the other parameters should be changed as shown in Table 5.

Table 5. The Results of Changing the Value of $Z_{0}$

\begin{tabular}{|c|c|c|c|}
\hline Symbols & Data & Symbols & Data \\
\hline \hline$r_{1}(\mathrm{~mm})$ & 30.194 & $\alpha(\mathrm{deg})$ & 27.997 \\
\hline$\eta(\mathrm{deg})$ & 6.493 & $\delta_{b 1}(\mathrm{deg})$ & 24.896 \\
\hline$\delta_{1}(\mathrm{deg})$ & 16.997 & $\delta_{b 2}(\mathrm{deg})$ & 57.033 \\
\hline$\delta_{2}(\mathrm{deg})$ & 71.839 & $d(\mathrm{~mm})$ & 33.767 \\
\hline$A_{1}(\mathrm{~mm})$ & 103.287 & $e(\mathrm{~mm})$ & 26.020 \\
\hline$A_{2}(\mathrm{~mm})$ & 92.782 & $\kappa(\mathrm{deg})$ & 10.745 \\
\hline$\varepsilon^{\prime}(\mathrm{deg})$ & 21.271 & $\gamma(\mathrm{deg})$ & 55.054 \\
\hline$\beta_{1}(\mathrm{deg})$ & 48.283 & $\varepsilon^{\prime}(\mathrm{deg})$ & 23.793 \\
\hline$\beta_{2}(\mathrm{deg})$ & 27.012 & $\beta_{b 1}(\mathrm{deg})$ & 48.027 \\
\hline$\alpha_{n}(\mathrm{deg})$ & 25.344 & $\beta_{b 2}(\mathrm{deg})$ & 24.234 \\
\hline
\end{tabular}

\section{CONCLUSIONS}

On the basis of the theory of generating-line method, this paper established the cutting geometry and base-cone parameters, and these researches made the new method suitable to manufacture hypoid gears. The cutting geometry contains the tangent relationships between pinion base cone and base plane, and between gear base cone and base plane, respectively, and also contains the planar conjugated relationship between two generating lines of pinion and gear.
The base-cone parameters determine the relationships among base cones, base plane and generating lines, and they are necessary to be used to establish the coordinate systems and the equations of generating lines. It can be seen from the example, if some of the base-cone parameters need to be adjusted, it can be realized by modify the value of the parameter $r_{2}, \varepsilon$ or $Z_{0}$.

\section{ACKNOWLEDGEMENTS}

This work was supported by Research Fund for the Doctoral Program of Higher Education of China (Grant No. 20090061110023), Key Program of Technology Development of Jilin Province (Grant No. 20080346) and Graduate Innovation Fund of Jilin University (Grant No.20101019), and the authors would like to thank their financial supports.

\section{REFERENCES}

[1] E. Wildhaber, "Basic Relationship of Hypoid Gears I-VII", American Machinist, vol. 90, pp. 108-111, pp. 131-134, February 1946; vol. 90, pp. 132-135, March 1946; vol. 90, pp. 110-114, pp. 150-152, June 1946; vol. 90, pp. 106-110, July 1946; vol. 90, pp. 104-106, pp. 122-128, August 1946.

[2] M. L. Baxter, "Basic geometry and tooth contact of hypoid gears", Ind. Math., vol. 11, pp. 19-42, 1961.

[3] Y. P. Shih, Z. H. Fong, and Grandle C. Y. Lin, "Mathematical model for a universal face hobbing hypoid gear generator", $J$. Mech. Des., vol. 129, pp. 38-47, January 2007.

[4] Q. Fan, "Computerized modeling and simulation of spiral bevel and hypoid gears manufactured by gleason face hobbing process", $J$. Mech. Des., vol. 128, pp. 1315-1327, November 2006.

[5] Q. Fan, "Enhanced algorithms of contact simulation for hypoid gear drives produced by face-milling and face-hobbing processes", J. Mech. Des., vol. 129, pp. 31-37, January 2007.

[6] Q. Fan, "Tooth surface error correction for face-hobbed hypoid gears", J. Mech. Des., vol. 132, pp. 011004-1-8, January 2010.

[7] V. Simon, "Optimal machine tool setting for hypoid gears improving load distribution", J. Mech. Des., vol. 123, pp. 577-582, December 2001.

[8] V. Simon, "Optimal tooth modifications in hypoid gears", J. Mech. Des., vol. 127, pp. 646-655, July 2005.

[9] V. Simon, "Design and manufacture of spiral bevel gears with reduced transmission errors", J. Mech. Des., vol. 131, pp. $041007-$ 1-11, April 2009.

[10] J. L. Wu, C. C. Liu, C. B. Tsay, and S. Nagata, "Mathematical model and surface deviation of helipoid gears cut by shaper cutters", J. Mech. Des., vol. 125, pp. 351-355, June 2003.

[11] Y. C. Tsai, and P. C. Chin, "Surface geometry of straight and spiral bevel gears", J. Mech. Trans. Autom. Des., vol. 109, pp. 443-449, December 1987.

[12] M. J. Al-Daccak, J. Angeles, and M. A. González-Palacios, "The modeling of bevel gears using the exact spherical involute", $J$. Mech. Des., vol. 116, pp. 364-368, June 1994.

[13] Z. J. Yang, F. H. Peng, and X. C. Zhang, "Cutting method and machine tool of spherical involute tooth profile spiral bevel gear," China Patent 200810051354.3, March 25, 2009.

[14] F. H. Peng, Involute Gear Cutting on the Tracing Line, China: Jilin Science and Technology Press, 2008.

[15] F. L. Litvin, Gear Geometry and Applied Theory, USA: Cambridge University Press, 2004.

This is an open access article licensed under the terms of the Creative Commons Attribution Non-Commercial License (http: //creativecommons.org/licenses/by$\mathrm{nc} / 3.0 /$ ), which permits unrestricted, non-commercial use, distribution and reproduction in any medium, provided the work is properly cited. 